\title{
A mortality cohort study in a north Italian aircraft factory
}

\author{
G COSTA,' F MERLETTI, ${ }^{2}$ N SEGNAN ${ }^{1}$ \\ From the Unit of Epidemiology, ${ }^{1}$ Local Health Authority of Turin, and Unit of Cancer Epidemiology, ${ }^{2}$ \\ Department of Biomedical Sciences and Human Oncology, University of Turin, Turin, Italy
}

ABSTRACT Mortality in a cohort of 8626 workers employed between 1954 and 1981 in an aircraft manufacturing factory in northern Italy was studied. Total follow up was 132042 person-years, witho $76 \%$ accumulated in the age range 15 to 54 . Median duration of follow up from the date of first employment was 16 years. Vital status was ascertained for $98.5 \%$ of the cohort. Standardisedf5 mortality ratios were calculated based on Italian national mortality rates. Altogether 685 deaths-

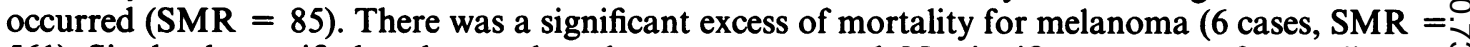
561). Six deaths certified as due to pleural tumours occurred. No significant excess of mortality was found in specific jobs or work areas.

A retrospective cohort study of mortality in an aircraft manufacturing plant near Turin, northern Italy, was carried out to investigate an apparently high number of malignant tumours among employees that were brought to the attention of the local health authority by staff representatives.

The plant manufactures aircraft and aircraft/aerospace components and has been active from the beginning of the century. Processes are not dissimilar to those of transportation equipment manufacturing, with more sophisticated technologies and materials. Potential hazardous substances and physical factors have been used for these processes: aromatic nitro and amino organic compounds in cutting fluids and as constituents of rubber plastic paint dye; other aromatic and halogenated organic compounds in solvents; chromates and other heavy metal salts in paints and welding fumes; epoxy resins and other plastics with amine hardeners in fibre sheet preimpregnated materials, in paints and enamels, and in adhesive materials; fibres (asbestos, manmade mineral fibres) in insulating materials and composite materials; and ionising radiation in non-destructive testing.

\section{Materials and methods}

Complete personnel records of the company were available since August 1954 only, when full scale operations were resumed after the postwar years. The

Accepted 1 December 1988 workforce grew from about 1500 in 1954 to 3000 byơ the end of the 1950s and since then has fluctuatedo between 3000 and 3500 . For each employee persona $\bar{L}$ data and work histories within the plant (department 5 of work and job) were abstracted and coded by cleriog $P$ assistants of the plant under our guidance. A $\$ \%$ sample of the records were recoded for quality contor of data collection. No independent verification from sources other than company records was possible.

The study cohort includes 8626 individuals: $950 \mathrm{~B}$ women (636 clerks and 314 blue collar workers and technical staff such as foremen and supervisors) and 7676 men ( 5625 blue collar workers, 965 technicab staff, 571 administrative clerks, and 515 white collaț workers unspecified whether administrative or tech $-\overline{0}$ nical staff). These categories refer to first recordedp occupation since 1954. Employment began before 1954 for a subcohort of 1155 subjects. No minimum duration of service was introduced to allow के comparison between subjects with different periods o? service.

A cumulative distribution of the cohort by age, sex? and years of starting and leaving employment, dura tion of services, and of follow up is presented in table 1 . Half the employees had worked at least eight years af the plant; about half had been hired before 1965, thus allowing for a minimum follow up of 15 years, whereap at the beginning of the study 3536 employees $(41 \%)$ were still active in the factory. The vital status of the other employees (5090) was ascertained through the local vital registries of the place where they lived of died: among them 4278 (49.6\% of the total) were alive 
Table 1 Cumulative distribution (\%) of some time related characteristics of the cohort members

\begin{tabular}{|c|c|c|c|c|c|c|}
\hline & \multirow[b]{2}{*}{$\operatorname{Sex}$} & \multicolumn{5}{|c|}{ Scale (\%) } \\
\hline & & 0 & 25 & 50 & 75 & 100 \\
\hline Age at hiring & $\begin{array}{l}\mathbf{M} \\
\mathbf{F}\end{array}$ & $\begin{array}{l}15 \\
16\end{array}$ & $\begin{array}{l}21 \\
20\end{array}$ & $\begin{array}{l}25 \\
24\end{array}$ & $\begin{array}{l}31 \\
32\end{array}$ & $\begin{array}{l}63 \\
55\end{array}$ \\
\hline Age at leaving & $\begin{array}{l}\mathbf{M} \\
\mathbf{F}\end{array}$ & $\begin{array}{l}19 \\
17\end{array}$ & $\begin{array}{l}27 \\
28\end{array}$ & $\begin{array}{l}34 \\
35\end{array}$ & $\begin{array}{l}48 \\
48\end{array}$ & $\begin{array}{l}67 \\
63\end{array}$ \\
\hline Year of hiring & $\stackrel{\mathbf{M}}{\mathbf{F}}$ & $\begin{array}{l}1916 \\
1925\end{array}$ & $\begin{array}{l}1956 \\
1956\end{array}$ & $\begin{array}{l}1963 \\
1969\end{array}$ & $\begin{array}{l}1972 \\
1972\end{array}$ & $\begin{array}{l}1981 \\
1981\end{array}$ \\
\hline Year of leaving & $\begin{array}{l}\mathbf{M} \\
\mathbf{F}\end{array}$ & $\begin{array}{l}1954 \\
1954\end{array}$ & $\begin{array}{l}1965 \\
1971\end{array}$ & $\begin{array}{l}1977 \\
1981\end{array}$ & & \\
\hline $\begin{array}{l}\text { Duration of service } \\
\text { (y) }\end{array}$ & $\begin{array}{l}\mathbf{M} \\
\mathbf{F}\end{array}$ & $\begin{array}{l}1 \\
1\end{array}$ & $\begin{array}{l}3 \\
4\end{array}$ & $\begin{array}{r}9 \\
11\end{array}$ & $\begin{array}{l}18 \\
16\end{array}$ & $\begin{array}{l}49 \\
42\end{array}$ \\
\hline $\begin{array}{l}\text { Duration of follow } \\
\text { up (y) }\end{array}$ & $\underset{\mathbf{F}}{\mathbf{M}}$ & $\begin{array}{l}1 \\
1\end{array}$ & $\begin{array}{l}10 \\
10\end{array}$ & $\begin{array}{l}17 \\
13\end{array}$ & $\begin{array}{l}26 \\
25\end{array}$ & $\begin{array}{l}59 \\
54\end{array}$ \\
\hline
\end{tabular}

on 30 June 1981, $685(7.8 \%)$ were dead, $71(0.82 \%)$ could not be traced, and $56(0.65 \%)$ had emigrated.

Local vital registries provided copies of the death certificates. The causes of death were known for all but 15 of the subjects. The underlying cause of death was coded by a trained nosologist according to the ICD rules in effect at the time of death. Codes were then grouped into cause of death categories that were consistent across the International Classification of Diseases, 7th and 8th revisions, and presented in the form of the 8th revision.

Clinical data were searched in hospitals of Italy for subjects dying of cancer of the central nervous system (CNS), cancer of the rectum, melanomas, and pleural mesotheliomas. These sites were selected either because of an interest "a priori" (cancer of CNS, see
Discussion) or because of an excess found during the study.

Expected numbers of cause specific deaths were calculated by applying five year (1955-81) rates by age and sex for Italy to the person-years at risk. ${ }^{1}$ National rates were used, since local age specific rates have been available in Italy only since 1970 .

A total of 13436 person-years at risk for women and of 118606 person-years at risk for men were accumulated between 1 January 1954 and 30 June $1981,76 \%$ of which were in the age range 15 to 54 . Individuals whose vital status was not known were treated as alive at the end of follow up. Analysis by individual occupational history refers to having ever been in a given job and work area. Computations were performed using the life table analysis system version D computer program. ${ }^{2}$ Standardised mortality ratios (SMRs) were calculated as the ratio of observed to expected numbers of deaths expressed as a percentage. Approximate confidence limits (two sides test based) were computed assuming a Poisson distribution for observed frequencies. Exact Fisher confidence limits were computed for observed frequencies of less than 8 . The programs developed by Rothman and Boice were used. $^{3}$

\section{Results}

\section{OVERALL MORTALITY}

Table 2 shows the general mortality by major causes of death among men. Overall mortality is significantly lower than expected. The deficit is in all major causes of death. The pattern is similar among blue collar workers, technical staff, and white collar workers not otherwise specified (NOS). Administrative clerks show slightly higher mortality based on a small number.

able 2 Observed deaths and SMRs by cause for male blue collar workers, technical staff members, administrative clerks, and clerks not therwise specified (NOS)

\begin{tabular}{|c|c|c|c|c|c|c|c|c|c|c|}
\hline \multirow[b]{2}{*}{$\begin{array}{l}\text { Tause of death } \\
\text { ICD 8th rev) }\end{array}$} & \multicolumn{2}{|c|}{$\begin{array}{l}\text { Blue collar workers } \\
(n=5625 / p y=91579)\end{array}$} & \multicolumn{2}{|c|}{$\begin{array}{l}\text { Technical staff } \\
(n=965 / p y=12002)\end{array}$} & \multicolumn{2}{|c|}{$\begin{array}{l}\text { Admin clerks } \\
(n=571 / p y=5484)\end{array}$} & \multicolumn{2}{|c|}{$\begin{array}{l}\text { White collar NOS } \\
(n=515 / p y=9540)\end{array}$} & \multicolumn{2}{|c|}{$\begin{array}{l}\text { Total male cohort } \\
(n=7676 / p y=118606)\end{array}$} \\
\hline & Obs & $\begin{array}{l}S M R \\
(C L 95 \%)\end{array}$ & Obs & $\begin{array}{l}S M R \\
(C L 95 \%)\end{array}$ & Obs & $\begin{array}{l}S M R \\
(C L 95 \%)\end{array}$ & Obs & $\begin{array}{l}S M R \\
(C L 95 \%)\end{array}$ & Obs & $\begin{array}{l}S M R \\
(C L 95 \%)\end{array}$ \\
\hline Ull causes & 493 & $\begin{array}{l}84 \\
(77-92)\end{array}$ & 71 & $\begin{array}{l}85 \\
(67-107)\end{array}$ & 42 & 112 & 36 & 60 & 642 & 83 \\
\hline $\begin{array}{l}\text { Malignant neoplasms } \\
(140-209)\end{array}$ & 129 & $\begin{array}{l}89 \\
(74-105)\end{array}$ & 20 & $\begin{array}{l}96 \\
(58-147)\end{array}$ & 8 & $\begin{array}{l}87 \\
(37-171)\end{array}$ & 11 & $\begin{array}{l}72 \\
(36-130)\end{array}$ & 168 & $\begin{array}{l}88 \\
(75-102)\end{array}$ \\
\hline $\begin{array}{l}\text { irculatory system } \\
(390-458)\end{array}$ & 204 & $\begin{array}{l}94 \\
(81-107)\end{array}$ & 32 & 104 & 17 & $\begin{array}{l}119 \\
(69-191)\end{array}$ & 15 & $\begin{array}{l}67 \\
(37-111)\end{array}$ & 268 & $\begin{array}{l}94 \\
(83-106)\end{array}$ \\
\hline $\begin{array}{l}\text { 2espiratory system } \\
(460-519)\end{array}$ & 28 & $\begin{array}{l}66 \\
(44-96)\end{array}$ & 2 & 33 & 1 & 37 & 4 & $\begin{array}{l}91 \\
(25-232)\end{array}$ & 35 & $\begin{array}{l}63 \\
(44-88)\end{array}$ \\
\hline $\begin{array}{l}\text { Digestive system } \\
(520-577)\end{array}$ & 45 & $\begin{array}{l}82 \\
(60-110)\end{array}$ & 2 & 26 & 4 & $\begin{array}{l}117 \\
(32-299)\end{array}$ & 3 & $\begin{array}{l}55 \\
(11-162)\end{array}$ & 54 & $\begin{array}{l}76 \\
(57-99)\end{array}$ \\
\hline $\begin{array}{l}\text { Jenitourinary system } \\
(580-607)\end{array}$ & 4 & $\begin{array}{l}37 \\
(10-95)\end{array}$ & 1 & 66 & 3 & $\begin{array}{l}441 \\
(91-1289)\end{array}$ & 0 & - & 8 & $\begin{array}{l}57 \\
(25-113)\end{array}$ \\
\hline $\begin{array}{l}\text { tccidents, poison, and } \\
\text { violence }(800-999)\end{array}$ & 50 & $\begin{array}{l}73 \\
(54-97)\end{array}$ & 9 & $\begin{array}{l}101 \\
(46-191)\end{array}$ & 7 & $\begin{array}{l}174 \\
(70-358)\end{array}$ & 1 & 14 & 67 & $\begin{array}{l}76 \\
(59-96)\end{array}$ \\
\hline Jther causes & 33 & $\begin{array}{l}68 \\
(47-95)\end{array}$ & 5 & $\begin{array}{l}73 \\
(24-170)\end{array}$ & 2 & 65 & 2 & 42 & 42 & $\begin{array}{l}66 \\
(48-89)\end{array}$ \\
\hline
\end{tabular}

эy $=$ Person-years. 
SMRs for female blue collar workers and technical staff are 131 for all causes (based on 26 observed) and 160 for all malignancies (based on nine observed). Corresponding figures for female clerks are 88 (17 observed) and 112 (seven observed). The size of these groups, however, is small and no cluster of cases of cancer at specific sites is identified.

In the following tables results are presented only for the cohort of 7105 men working in manufacturing areas and including blue collar workers and techncal staff. White collar workers not specified as office workers are also included in this group because of the high likelihood of their having been technical staff.

\section{SPECIFIC CAUSES OF DEATH}

Table 3 lists observed deaths and SMRs for specific causes. Most of the common types of cancer occur less often in this group than in the general population. Excesses of cancer of the rectum (10v5.89) and prostate $(10 \vee 7.33)$ are not statistically significant. Five deaths from melanoma $(0.98$ expected) were observed. One further case occurred among female blue collar workers $v 0.04$ expected. No melanomas were observed among male and female administrative clerks $v 0 \cdot 1$ expected. The category of cancers of lung and pleura includes five deaths from tumours of the pleura. One more pleural tumour occurred among administrative clerks.

\section{TEMPORAL CONSIDERATIONS}

Mortality by specific cause is examined separately in the two groups first employed before and after 1954, the former being the surviving or cross sectional and the latter the "in-take" part of the cohort (table 3). In both groups SMRs for total mortality are significantly lower than 100. The deficit extends to all major disease categories, except circulatory diseases in those first employed before 1954 and malignant neoplasms in those first employed after 1954 (SMRs close to 100).

Excess risks for rectum and prostate cancers are confined to the first subcohort (respectively $10 v 4 \cdot 1$ and $9 v 6 \cdot 3$ ). Four of six cases of tumours of the pleura were also in subjects of this group. All five cases of melanoma occurred in the subcohort first employed after 1954, resulting in an SMR of 848. If the female case is also considered six cases $v 0.63$ expected occurred in this group.

Table 4 shows the analysis by duration of employment, allowing for a minimum of 15 years of follow up. In the second subcohort risk for melanoma increases with duration of employment; risk for lung cancer shows an increasing trend with a small excess in the longer duration of employment and risk for haematolymphopoietic tumours shows an overall excess (6 v 2.57, SMR 233, CL 95\% 86-508). Risk for rectal cancer is limited to the first subcohort.
Mortality by job (14 categories) shows a small excess $c$ for all causes and all malignancies among unskillec manual workers (30v21.4 and $10 v 5.7)$. An excess is found for rectal cancer among fitters $(4 v 1.32)$, lung. and pleural cancer among testers (6 $v 3.75)$, melanomat: $(2 v 0.08)$, and haemolymphopoietic tumours $(3 v 0.95 \%$ among workbench men.

Mortality by work area (16 categories) shows exces? tumours of buccal cavity and pharynx in heat treat $\frac{5}{5}$. ment $(3 v 0 \cdot 70)$, melanomas $(2 v 0 \cdot 14)$ and prostate $(3 \Phi$ $1.07)$ in metal forming, urinary organs in machining ( 4 $v 1.99)$, haematolymphopoietic $(3 v 1.27)$ and rectum (3 $v 0.85)$ in two different and specific assembling areas, stomach $(6 v 2.97)$ in fixture and joinery, and stomach $(4 v 1.82)$ in maintenance.

INDIVIDUAL CHARACTERISTICS OF PEOPLE DYING FOR SPECIFIC CANCER SITES

The six cases of melanoma had been hired after 1954: mean age at death was 43; latency from firs? employment in the factory ranged from eight to $1 \Phi_{0}$ years and duration of employment from one to eight years. No death from melanoma was observed among the 1113 office clerks of both sexes against $0 \cdot 10$ expected. Individual work histories did not sugges any obvious cluster of jobs or operations, although alp men were employed at the plant at the same time during the 1960 s. Clinical records reported that melan $\overrightarrow{0}$ omas were located in the leg in three cases and in trunk for the remaining three.

The six tumours of the pleura (ICD 163.0, 8th teiv were treated in the analysis with lung cancer because the reference mortality data for this cancer have been available in Italy only since 1969 . Nevertheless, 0.5 क्ष pleural tumours were expected during 1969-81 (afte? the introduction of the ICD 8th rev in Italian mortality $\overrightarrow{\overrightarrow{0}}$ statistics) among men, blue collar workers, and tech 3 nical staff, against five observed. All cases were mer with a mean age at death of 70 ; five were aged 35 or. over at the time of first employment in the factory Work histories included many different jobs (assem 3 bler, plumber, joiner, turner, or technical staff). Diag noses were mostly based on radiological findings. NF. case was necropsied. Two subjects were not smokers according to clinical records.

SMRs for tumours of the CNS among male blue collar workers and technical staff was $79(3 \vee 3.8)$ when malignant tumours (ICD 191, 8th rev) were cons sidered. The ratio of observed to expected was $7 v 6.96$. when CNS tumours of unspecified nature (ICD 238, 8th rev) and CNS benign tumours (ICD 225, 8th revS were also considered. No cases were observed among female and male clerks. The available work histories did not suggest any cluster of jobs or work areas affected. Clinical records could not be traced for three cases and were poor for two; the remaining two 
Table 3 Observed deaths by cause and SMRs for male blue collar workers and technical staff by year of hiring

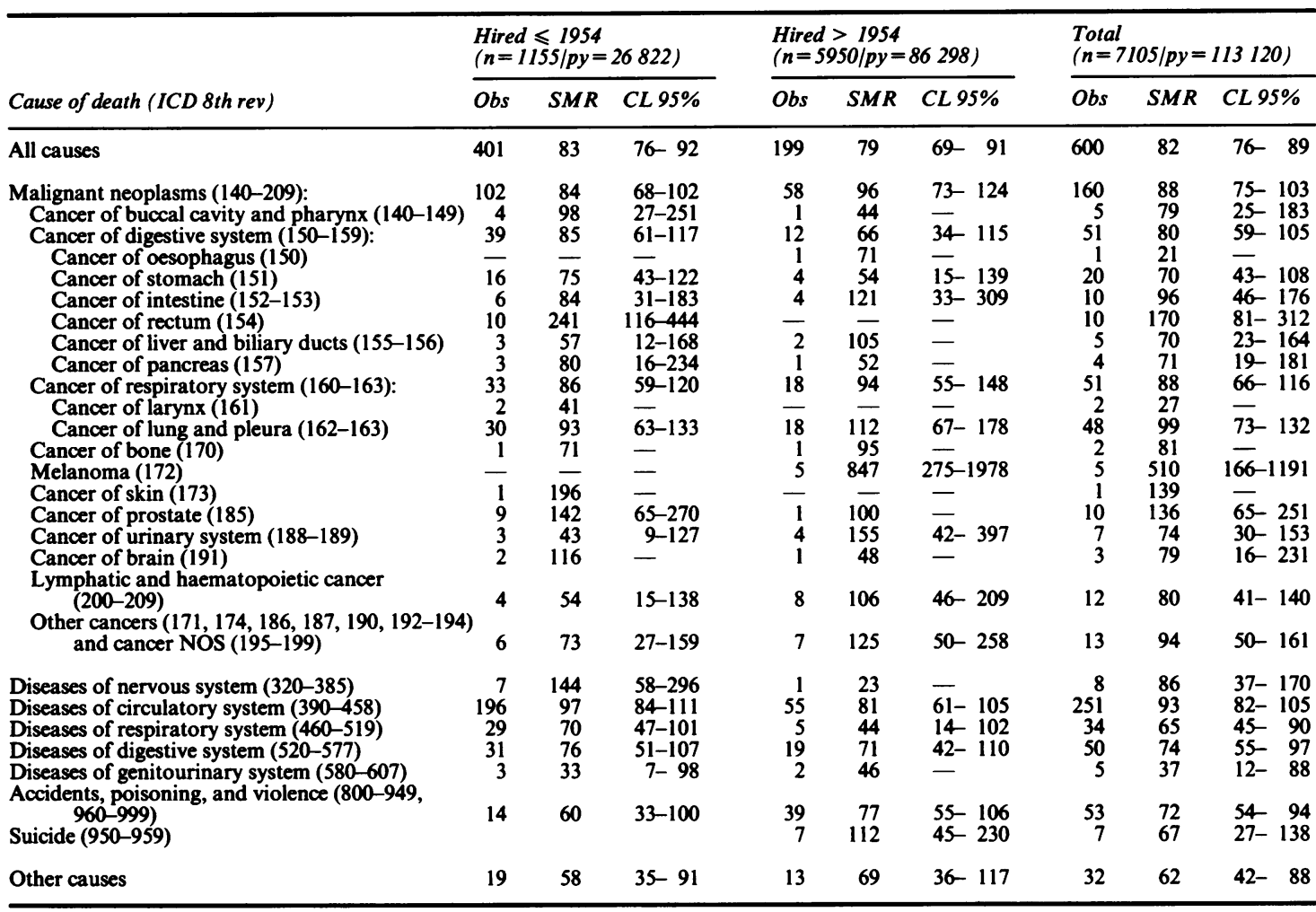

py $=$ Person-years

included a histologically confirmed glioma and a carcinoma of paranasal sinuses.

All cases of rectal cancer had been first employed in the factory before 1954. Five had been working in assembling areas, mostly with fitting jcbs. Clinical records were traced for five cases: in four the evidence of the rectum as the origin of the cancer was strong; in one case it was not possible to discriminate between colon and rectum.

\section{Discussion}

Mortality of aircraft manufacturing employees has been described in a limited number of studies. Garabrant et al in a cohort of 14067 subjects employed between 1958 and 1982 found non-significant excesses of cancer of the oesophagus (O/E 14/ $12 \cdot 3)$, pancreas $(34 / 28 \cdot 5)$, and bladder $(17 / 13 \cdot 4){ }^{4}$ The study found no excess of melanoma (5/9.3), mesothelioma, or neoplasms of the CNS. The surveillance study of proportional mortality by occupation in Washington State showed significant excesses for all malignant neoplasms and for some cancer sites (including some digestive organs, haematolymphopoietic system, and melanomas) among aeronautical engineers of different companies and among Boeing officials, managers, and supervisors. ${ }^{5}$ In aeronautical engineers aged under 65 proportional mortality ratios (PMR) for melanomas were twice as high as expected. Boeing workers not otherwise classified showed only a small but significant PMR increase for coronary heart diseases. Moreover, airplane mechanics, repairmen, and electricians, not necessarily employed at the Boeing company, showed a significant excess risk of CNS tumours. A preliminary investigation of CNS neoplasms in Los Angeles County (another United States area of high density of aircraft industry) showed excess risk among aircraft manufacturing employees, in particular for engineers. ${ }^{6}$

Our study, as of 1981, finds no excess either for oesophageal cancer or for CNS tumours. The study had $56 \%$ and $71 \%$ powers to detect any significant risk greater than twofold at the $5 \%$ significance level for these two cancer sites respectively. 
Table 4 Observed deaths and SMRs by cause for male blue collar workers and technical staff by year of hiring and duration of employment, allowing for 15 years of follow up

\begin{tabular}{|c|c|c|c|c|c|c|c|c|c|c|c|c|}
\hline \multirow[b]{3}{*}{ Cause of death (ICD 8th rev) } & \multicolumn{6}{|c|}{ Hired $\leqslant 1954$} & \multicolumn{6}{|c|}{ Hired $>1954$} \\
\hline & \multicolumn{2}{|l|}{$0-4$} & \multicolumn{2}{|l|}{$5-14$} & \multicolumn{2}{|l|}{$\geqslant 15$} & \multicolumn{2}{|l|}{$0-4$} & \multicolumn{2}{|l|}{$5-14$} & \multicolumn{2}{|c|}{$\geqslant 15$} \\
\hline & Obs & $S M R$ & Obs & $S M R$ & Obs & $S M R$ & Obs & $S M R$ & Obs & $S M R$ & Obs & $S M R$ \\
\hline All causes & 2 & 107 & 30 & 84 & 350 & 83 & 28 & 84 & 26 & 80 & 39 & 93 \\
\hline Malignant neoplasms (140-209): & - & 一 & 5 & 59 & 94 & 87 & 9 & 95 & 11 & 121 & 14 & 112 \\
\hline Buccal cavity and pharynx $(140-149)$ & - & - & - & - & 4 & 111 & - & - & - & - & - & - \\
\hline Digestive system (150-159): & 1 & 555 & 2 & 64 & 35 & 87 & 3 & 120 & 2 & 83 & 2 & 555 \\
\hline Oesophagus (150) & - & 一 & - & - & - & $\overline{7 \varepsilon}$ & - & 一 & 1 & 87 & - & - \\
\hline Stomach (151) & - & - & 1 & 69 & 14 & 75 & - & $\overline{20}$ & 1 & 185 & 1 & 141 \\
\hline Intestine $(152,153)$ & - & - & - & - & 6 & 94 & 1 & 370 & - & - & 1 & 278 \\
\hline Rectum (154) & 一 & - & 1 & 333 & 9 & 244 & - & $\overline{7}$ & - & - & 一 & - \\
\hline Liver and biliary ducts $(155-156)$ & - & $\overline{0}$ & - & - & 3 & 66 & 2 & 714 & - & - & - & - \\
\hline Pancreas (157) & 1 & 5000 & - & $\overline{-10}$ & 2 & 60 & - & - & - & - & - & - \\
\hline Respiratory system (160-163): & - & - & 2 & 78 & 31 & 90 & 2 & 59 & 2 & 63 & 6 & 125 \\
\hline Larynx (161) & - & - & $\overline{2}$ & $\overline{02}$ & 2 & 46 & - & - & - & - & - & $\overline{17}$ \\
\hline Lung and pleura (162-163) & - & - & 2 & 93 & 28 & 97 & 2 & 70 & 2 & 74 & 6 & 147 \\
\hline Bone (170) & 一 & - & - & 一 & 1 & 81 & - & $\overline{11}$ & - & - & - & - \\
\hline Melanoma (172) & - & - & - & - & - & $\overline{27}$ & 1 & 1111 & 3 & 4412 & 一 & - \\
\hline Skin (173) & - & - & - & $\overline{51}$ & 1 & 227 & - & 一 & 一 & - & 一 & - \\
\hline Prostate (185) & 一 & - & 2 & 351 & 7 & 123 & - & $\overline{0}$ & 1 & 357 & - & - \\
\hline Urinary system (188-189) & 一 & - & - & - & 3 & 48 & 1 & 217 & 1 & 213 & 1 & 161 \\
\hline Brain (191) & 一 & - & 一 & - & 2 & 133 & 一 & - & - & 一 & - & - \\
\hline$(200-209)$ & - & - & - & - & 4 & 62 & 2 & 244 & 2 & 270 & 2 & 198 \\
\hline Other $(171,174,186,187,190,192-194)$ & & & & & & & & & & & 2 & \\
\hline and cancer NOS (195-199) & - & - & - & - & 6 & 84 & - & - & - & - & 3 & 291 \\
\hline Disease of nervous system $(320-385)$ & - & - & $\overline{10}$ & $\overline{10}$ & 7 & 167 & - & - & - & - & 1 & 192 \\
\hline Disease of circulatory system $(390-458)$ & 2 & 264 & 19 & 118 & 168 & 94 & 11 & 102 & 9 & 79 & 12 & 87 \\
\hline Disease of respiratory system $(460-519)$ & - & - & 3 & 93 & 19 & 52 & 1 & 64 & - & - & - & $\overline{7}$ \\
\hline Disease of digestive system $(520-577)$ & 一 & - & 1 & 36 & 27 & 75 & 3 & 73 & 1 & 27 & 4 & 76 \\
\hline Disease of genitourinary system (580) & - & - & 1 & 145 & 1 & 13 & - & - & - & - & - & - \\
\hline \multicolumn{13}{|l|}{ Accidents, poisonings, and violence } \\
\hline$(800-949,960-998)$ & 一 & 一 & 一 & 一 & 11 & 57 & 3 & 79 & 3 & 94 & 5 & 1210 \\
\hline Suicide $(950-959)$ & - & 一 & - & $\overline{1}$ & - & - & - & - & 2 & 364 & 1 & 1430 \\
\hline Other causes & 一 & - & 1 & 45 & 18 & 65 & 1 & 52 & 一 & 一 & 2 & 84 드. \\
\hline
\end{tabular}

The healthy worker effect may be seen operating differently in this cohort: lower mortality among male blue collar workers and technical staff may be due to selective hiring of healthy employees. SMRs for all causes among male administrative clerks and among all women were higher than 100 . This may reflect the absence of health selection.

In our study there was an excess of deaths from pleural cancer, cancers of the rectum, and melanomas in male blue collar workers and technical staff.

The increased risk for tumours of the pleura is particularly in people with a long duration of follow up and of employment from the early 1940-50s. This finding is interesting but is obscured by poor reliability of diagnoses. No cases of asbestosis nor excess risk for lung cancer are reported in the study. At present asbestos is not used in the plant but past uses cannot be ruled out. Exposures to asbestos in work before hiring in the plant cannot be ruled out. On the other hand, the finding of an excess of pleural cancer cannot be dismissed on these grounds, because manmade mineral fibres were used at the plant from 1954, mainly in composite materials.
Clinical record retrieval has not provided a definite discrimination between cancers of the rectum and $\mathrm{Q}^{\varrho}$ colon for six of 10 cases. Pulling together the two sites, a non-significant excess is found in the group hired 3 before 1954 with 16 observed against 11.28 expected (SMR 142, CL 95\% 81-230); this residual excess could? be partly explained by the choice of the Italiano population as a reference, which has a colon/rectum 3 cancer mortality substantially lower than the regionalo one.?

With regard to melanomas, there are no reasons too think that survival for melanoma is lower in Turin than in the rest of Italy, nor that the use of regionalo mortality as a reference may change substantially the $\mathrm{O} / \mathrm{E}$ ratio. Based on individual work histories, noo particular job is affected by the risk. Nevertheless, all five male cases were employed at the factory at theo same time during the early 1960 s, when some aircraft $N$ projects necessitated extensive use of polysulphide resin based adhesives. Epoxy resins were introduced in paints and in fibreglass reinforced plastics, mainly in assembling areas, where four out of five cases had been? employed in this period for any length of time. All six@ 
melanomas were located on areas of the body surface that are usually covered.

Our findings are consistent with those of Milham's surveillance system ${ }^{5}$ whereas no excess for melanomas was found by Garabrant. ${ }^{4}$ A recent review of specific agents and economic activities possibly associated with melanoma may suggest a concentration of cases in high technology industries such as ours. ${ }^{8}$ This may be confounded by the known role of higher social class. ${ }^{8}$ On the other hand, in our study five of six cases were blue collar workers.

Our findings suggest an increased risk for melanomas among the younger workers, employed more recently and working in manufacturing areas. Given that exposures are multiple, a specific chemical or other cause for this excess cannot be hypothesised.

In conclusion, this study shows an increased risk of death for melanoma and possibly for tumours of the pleura in this aircraft industry. Difficulties in investigating the role of specific chemicals or physical risk factors hindered the interpretation of these findings.

This study was made possible by a grant from the company to the unit of epidemiology of the Local Health Authority of Turin. We are indebted to Benedetto Terracini and David Garabrand for reviewing the manuscript and to Rossana Prandi and Ernesto Bertagna for clerical help.
Requests for reprints to: Dr G Costa, Unit of Epidemiology, National Health Service, via $S$ Francesco da Paola 31, 10123 Turin.

\section{References}

1 Zocchetti C, Bertazzi PA. Un programma computerizzato per l'analisi di studi di coorte di mortalità negli ambienti di lavoro. Med Lav 1982;73:9-21.

2 Waxweiler RJ, Beaumont JJ, Henry JA, et al. A modified life-table analysis system for cohort studies. J Occup Med 1983;25: 115-24.

3 Rothman KJ, Boice JD. Epidemiologic analysis with a programmable calculator. Washington: National Institutes of Health, 1979. (Publ No 79-1649.)

4 Garabrant DH, Held J, Langholz B, Berstein L. Mortality of aircraft manufacturing workers in southern California. Am J Ind Med 1988;13:683-93.

5 Milham S. Occupational mortality in Washington State 1950-79. Cincinnati: US Department of Health and Human Services (National Institute of Occupational Safety and Health) 1983. (Publ No 83-116.)

6 Preston-Martin S, Henderson BE, Peters JM. Descriptive epidemiology of central nervous system neoplasms in Los Angeles County. Ann NY Acad Sci 1982;381:202-8.

7 Capocaccia R, Farchi G, Mariotti S, et al. La mortalità in Italia nel periodo 1970-79. Rome: Istituto Superiore di Sanità, 1984. (Rapporto ISTISAN 84/10.)

8 Austin DF, Reynolds P. Occupation and malignant melanoma of the skin. Recent Results in Cancer Research 1986;102:98-107.

\section{Correspondence and editorials}

The British Journal of Industrial Medicine welcomes correspondence relating to any of the material appearing in the journal. Results from preliminary or small scale studies may also be published in the correspondence column if this seems appropriate. Letters should be not more than $\mathbf{5 0 0}$ words in length and contain a minimum of references. Tables and figures should be kept to an absolute minimum. Letters are accepted on the understanding that they may be subject to editorial revision and shortening.

The journal now also publishes editorials which are normally specially commissioned. The Editor welcomes suggestions regarding suitable topics; those wishing to submit an editorial, however, should do so only after discussion with the Editor. 